\title{
Kinematics of Hip, Knee and Ankle During Cross- Slope Walking
}

\author{
Mohsen Damavandi ${ }^{*}$ \\ 1. Department of Sports Biomechanics, Faculty of Sport Sciences, Hakim Sabzevari University, Sabzevar, Iran.
}

Citation: Damavandi M. Kinematics of hip, knee and ankle during cross-slope walking. Physical Therapy. 2015; 5(2):89-96. http://dx.crossref. org/10.15412/J.PTJ.07050204

: http://dx.crossref.org/10.15412/J.PTJ.07050204

Article info:

Received: 13 Feb. 2015

Accepted: 25 May 2015

Keywords:

Gait, Biomechanics, Kinematics, Lower extremity

\begin{abstract}
A B S T RA C T
Purpose: Little information is available on joint kinematic adaptations during walking on crossslope surfaces (i.e. a surface incline perpendicular to the direction of locomotion). This study aimed to evaluate the effects of cross-slope surfaces on three-dimensional (3D) kinematics of hip, knee, and ankle joints during stance phase of walking.
\end{abstract}

Methods: This is a quasi-experimental study. Ten healthy adult male students were selected through available sampling method and walked along an inclinable walkway in both level $\left(0^{\circ}\right)$ and cross-slope $\left(10^{\circ}\right)$ configurations. The 3D angles of hip, knee, and ankle along with their time of occurrence (the time reaching to the maximum values for each specific joint angle) were analyzed using repeated measures multivariate analysis of variance (MANOVA) by SPSS 17. $\mathrm{P}<0.05$ was considered significant.

Results: Knee and ankle joints had the most kinematic adaptations on cross-slope conditions in the sagittal plane, while in the transverse plane angles of hip and knee joints were mainly altered $(\mathrm{P}<0.05)$. These adaptations are necessary to adjust the functional leg-length during different stance phases to both maintain a subtle gait pattern and medio-lateral balance. Though significant differences in timing of the joints kinematic events between level and cross-slope walking were observed $(\mathrm{P}<0.05)$, their temporal aspects of the kinematic adaptations were more consistent than their magnitude.

Conclusion: The information obtained from this study enriches our understanding about the kinematic adaptations of the lower extremity joints in stance phase during level and cross-slope walking.

\footnotetext{
* Corresponding Author:

Mohsen Damavandi, $P h D$

Address: Department of Sports Biomechanics, Faculty of Sport Sciences, Hakim Sabzevari University, Sabzevar, Iran.

Phone: +98 (51) 44012767

E-mail:mohsen.damavandil@gmail.com
} 


\section{Introduction}

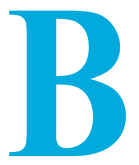

iomechanics research on gait has largely focused on level walking [1-3]. However, in daily life, we must regularly step on crossslope surfaces (i.e. a surface incline perpendicular to the direction of locomotion) that may be inclined up to $10^{\circ}$ and even more when traversing a cross-walk on a steeply inclined street. Despite the prevalence of cross-slopes in our environment, we know little about segmental adaptations necessary to maintain both balance and forward locomotion. Sidewalks and roadways with irregular or prolonged cross-slopes may impede walking and increase the risk of fall and lower extremity injuries, particularly in individuals with decreased motor function (e.g. the elderly).

Only a few studies have focused on cross-slope walking [4-6]. These studies usually evaluated the adaptations of either a single joint (e.g. the knee) or sub-segmental coordination of a specific limb (e.g. the hindfoot and forefoot) during cross-slope walking. Cross-slope locomotion is analogous to a leg length discrepancy adaption, in which the up- and down-slope limbs must functionally shorten and lengthen, respectively, to keep the body vertical [7].

In addition to the joints kinematic alteration in the sagittal plane, cross-slope walking would decrease inversion of the up-slope ankle and increase inversion of the down-slope ankle [5]. These kinematic adaptations during cross-slope walking could place the ankles at risk for both medial (up-slope) and lateral (down-slope) ankle complex ligament injury [8]. While for young adults, cross-slopes may not be a significant challenge, the asymmetrical demands of cross-slope walking could pose great functional muscular-skeletal and balance obstacles for special groups (elderly, amputees, etc.) [9].

Though the previous research reported substantial changes in the kinematics of cross-slope walking, no information is available regarding how the behaviors of hip, knee, and ankle joints during up- and down-slope walking are altered in relation to each other. To enhance forward locomotion and prevent the lower extremity injuries in cross-slope gait, the motion limitations of one joint should be compensated with the altered motions of the adjacent joints in the kinetic chain. This information is necessary to enhance our understanding of the underlying mechanisms involved in healthy and pathologic cross-slope gait.

It is hypothesized that the magnitude and temporal distribution (time of occurrence) of the lower extremity joints kinematics will differ substantially between level and cross-slopes, and the up-slope and down-slope limbs during walking. Therefore, this study aimed to determine the effects of cross-slope surfaces on three-dimensional (3D) kinematics of hip, knee, and ankle joints during stance phase of walking. Understanding the kinematic adaptations of the lower extremities during gait on cross-slope surfaces could help in designing orthoses, prostheses, and athletic footwear, as well as help therapists and physicians treat and avoid injuries in populations with restricted mobility (e.g. the elderly).

\section{Materials and Methods}

The study procedure was quasi-experimental with repeated measures.

\section{Study subjects}

The study population comprised all healthy adult male students at McGill University. Ten healthy adult males, with no history of gait abnormalities, and an average age of $25.4( \pm 8.6) \mathrm{y}$, height of $174.9( \pm 7.2) \mathrm{cm}$, and mass of $68.5( \pm 9.0) \mathrm{kg}$ were selected through available sampling method for this study. Because, significant differences in the lower extremity joints' kinematics were reported with a smaller sample size of 5 participants and cross-sloped $\left(2.5^{\circ}\right.$ and $\left.5^{\circ}\right)$ inclination angles [7] during gait, it was supposed that participation of 10 participants walking on $10^{\circ}$ cross-sloped surface will identify significant differences in kinematic adaptations of the hip, knee, and ankle joints in various conditions. The inclusion criteria were as follows: 1) no history of lower extremity injuries, and 2) leg length difference less than $2.0 \mathrm{~cm}$. Leg length was measured as the distance between the anterior superior iliac spine and the medial malleolus, via the knee joint, in a standing position, as specified in the ViconTM (Vicon, Los Angeles, USA) documentation. Subjects with a leg length difference exceeding $2.0 \mathrm{~cm}$ were excluded from the study. Before participating in this study, all participants signed a consent form, approved by the McGill University Research Ethics Board Office.

\section{Experimental set-up}

In this study, we used a 7-m transversely inclinable walkway with 1.2-m width. A force plate (AMTI, model OR6-5-1000, Watertown, MA, USA) was located in the middle of the walkway such that the participants could perform at least 3 steps on the ramp before hitting the force plate. Passive optical markers were placed over anatomical landmarks of the participants according to the Vicon Plug-in Gait model. To avoid slippage, the walkway and force plate were covered with an indoor running surface 
(Mondo America Inc., Laval, QC, Canada). A pilot testing indicated that the indoor running surface would not alter the magnitude and temporal distribution of the lower extremity joints kinematics as well as the force plate output during walking in various surface conditions.

Participants were familiarized to the walkway in both level $\left(0^{\circ}\right)$ and cross-slope $\left(10^{\circ}\right.$ transversely up- and downslope, respectively) walking conditions. Then, 10 selfselected speed barefoot walking trials at each condition were performed. Of them, 6 trials per condition with complete data sets were selected. The average speed of walking trials was $1.45( \pm 0.23) \mathrm{m} / \mathrm{s}$ on each surface condition ( $\mathrm{P}>0.18$ ). Because only the right leg was considered, for the cross-slope conditions, the participant walked in both directions while the right foot was in up-slope and downslope positions, respectively. If the participant's foot did not land completely on the force plate or if the subject targeted the platform, that trial would be excluded.

\section{Data acquisition}

Kinematic data were recorded at $240 \mathrm{~Hz}$ using an 8-camera ViconTM system (Vicon, Los Angeles, USA) and filtered using a fourth-order zero-phase lag Butterworth filter with an $8 \mathrm{~Hz}$ cut-off frequency. Force plate data were acquired at $960 \mathrm{~Hz}$ and filtered using a fourth-order low-pass Butterworth filter with a $20 \mathrm{~Hz}$ cut-off frequency. The force plate vertical force output was used to identify the heelstrike (HS) and toe-off (TO) events. The force plate was zeroed prior to collection on the cross-slope conditions to remove the effect of its weight on the output channels.

The dependent variables were the kinematic adaptations of hip, knee, and ankle joints across the selected events of stance phase and their time of occurrence, as a percent of stance, during level walking (LW), inclined walking upslope (IWU), and down-slope (IWD), respectively. The lower limb's joint angles calculated according to the method proposed by Grood and Suntay [10] were obtained from the Vicon Plug-in Gait model outputs.
Kinematic abbreviations and sign conventions used for the hip, knee, and ankle angles are presented in Table 1. For statistical analysis of the kinematic patterns, the lower limb's joint angles were taken at HS and TO in all 3 planes of motion. In addition, the maximum values for each specific joint angle were evaluated during walking in various surface conditions (Table 2). These parameters have been used extensively in the past for the study of walking [5, 11-14] in both normal and pathological gait.

\section{Statistical analysis}

The 3D angles of right hip, knee, and ankle joints and their time of occurrences at each event described above were averaged across all trials per condition in all participants during walking trials. Because the effect of surface conditions is generally represented by 2 or more of the dependent variables and the related assumptions (e.g. multivariate normality, homogeneity of covariance) were met, these angles were analysed using a between subject repeated measures MANOVA (statistical test of Wilk's lambda) by SPSS (SPSS Windows, version 17.0, Chicago, USA). The analyses was followed by a Bonferroni post hoc test if a statistical main effect for conditions was observed $(\alpha=0.05)$.

\section{Results}

During walking on level and cross-slope surfaces, the hip, knee, and ankle angles as well as the relative times plotted against percentage of stance showed distinct patterns of motion (Figure 1). Regarding the hip angles, significant differences were observed in the transverse plane. More specifically, the HER at IWD was greater than that of LW ( $\mathrm{P}=0.045)$ (Table 3). At TO, while the hip was externally rotated during IWU, it had an internal rotation at IWD $(\mathrm{P}=0.011)$. The timing of the selected events at the hip was more variable than its angle values. In the frontal plane, pairwise comparisons revealed that the HAD during LW occurred at $30.3 \%$ of stance which was significantly earlier than IWU $(35.2 \%$ of stance, $\mathrm{P}=0.027$ ) (Table 4). In the transverse plane, pairwise comparisons showed that the HER during IWU occurred earlier compared to those at LW and IWD (both $\mathrm{P}<0.001$ ), while the HIR occurred

Table 1. Kinematic abbreviations and sign conventions used for hip, knee, and ankle joints.

\begin{tabular}{cccc}
\hline Joint angles & Sagittal & Frontal & Transverse \\
\hline \multirow{2}{*}{ Hip } & Extension (Ext): - & Abduction (Abd): - & External rotation (ERot): - \\
& Flexion (Flx): + & Adduction (Add): + & Internal rotation (IRot): + \\
Knee & Extension (Ext): - & Abduction (Abd): - & External rotation (ERot): - \\
& Flexion (Flx): + & Adduction (Add): + & Internal rotation (IRot): + \\
Ankle & Plantar flexion (PF): - & Eversion (Eve): - & External rotation (ERot): - \\
& Dorsiflexion (DF): + & Inversion (Inv): + & Internal rotation (IRot): + \\
\hline
\end{tabular}


Table 2. Additional gait events used for comparisons of the kinematic parameters of hip, knee, and ankle joints during stance phase of walking.

\begin{tabular}{cccc}
\hline Joint & Sagittal & Frontal & Transverse \\
\hline \multirow{2}{*}{ Hip } & Maximum Ext $\left(\mathrm{H}_{\mathrm{EX}}\right)$ & Maximum Add $\left(\mathrm{H}_{\mathrm{AD}}\right)$ & Maximum IRot $\left(\mathrm{H}_{\mathrm{IR}}\right)$ \\
& & & Maximum ERot $\left(\mathrm{H}_{\mathrm{ER}}\right)$ \\
\multirow{2}{*}{ Knee } & Maximum Flx $\left(\mathrm{K}_{\mathrm{FX}}\right)$ & Maximum Add $\left(\mathrm{K}_{\mathrm{AD}}\right)$ & Maximum IRot $\left(\mathrm{K}_{\mathrm{IR}}\right)$ \\
& Maximum Ext $\left(\mathrm{K}_{\mathrm{EX}}\right)$ & Maximum Abd $\left(\mathrm{K}_{\mathrm{AB}}\right)$ & Maximum ERot $\left(\mathrm{K}_{\mathrm{ER}}\right)$ \\
Ankle & Maximum PF $\left(\mathrm{A}_{\mathrm{PF}}\right)$ & Maximum Eve $\left(\mathrm{A}_{\mathrm{EV}}\right)$ & Maximum ERot $\left(\mathrm{A}_{\mathrm{ER}}\right)$ \\
\hline
\end{tabular}

at $71.5 \%$ of stance during IWU which was significantly earlier than LW (78.9\% of stance, $\mathrm{P}=0.036)$ (Table 4).

Regarding the knee joint, the angle adaptions with respect to the different walking surface conditions occurred in 3 planes of motion (Table 3 ). In the sagittal plane, KFX during IWD was significantly greater than that of LW $(\mathrm{P}=0.033)$. Conversely at $\mathrm{TO}$, the knee flexion decreased significantly during IWD compared to $\mathrm{LW}(\mathrm{P}=0.028)$. In the frontal plane, pairwise comparisons revealed that the KAD during $\mathrm{LW}$ was smaller than those of IWU $(\mathrm{P}=0.009)$ and IWD $(\mathrm{P}<0.001)$. In the transverse plane and at TO, the

Table 3. Mean (SD) values of hip, knee, and ankle angles and associated mean differences across the selected events of stance phase in level walking (LW), inclined walking up-slope (IWU) and down-slope (IWD).

\begin{tabular}{|c|c|c|c|c|c|c|c|c|c|c|}
\hline \multirow[b]{2}{*}{ Joint } & \multirow[b]{2}{*}{ Plane } & \multirow[b]{2}{*}{ Event } & \multirow[b]{2}{*}{ LW } & \multirow[b]{2}{*}{ IWU } & \multirow[b]{2}{*}{ IWD } & \multirow[b]{2}{*}{$\mathbf{F}$} & \multicolumn{3}{|c|}{ Mean difference $\left({ }^{\circ}\right)$} & \multirow[b]{2}{*}{$n^{2}$} \\
\hline & & & & & & & $\begin{array}{c}\text { LW } \\
\text { VS } \\
\text { IWU }\end{array}$ & $\begin{array}{c}\text { LW } \\
\text { VS } \\
\text { IWD }\end{array}$ & $\begin{array}{l}\text { IWU } \\
\text { VS } \\
\text { IWD }\end{array}$ & \\
\hline \multirow{10}{*}{ Hip } & \multirow{3}{*}{ Sagittal } & $\mathrm{HS}$ & $23.5(2.2)$ & $25.0(2.2)$ & $24.6(1.8)$ & 1.26 & -1.5 & -1.1 & 0.4 & 0.085 \\
\hline & & HEX & $-21.1(3.8)$ & $-25.3(4.1)$ & $-25.5(3.6)$ & 2.53 & -4.2 & -4.4 & -0.2 & 0.064 \\
\hline & & TO & $-16.3(4.1)$ & $-18.9(3.1)$ & $-18.1(3.3)$ & 1.77 & -2.6 & -1.8 & 0.8 & 0.099 \\
\hline & \multirow{3}{*}{ Frontal } & HS & $-3.8(2.1)$ & $-5.0(2.8)$ & $-3.7(3.1)$ & 0.53 & -1.2 & 0.1 & 1.3 & 0.043 \\
\hline & & HAD & 3.1(1.6) & $3.1(1.4)$ & $3.3(2.2)$ & 0.31 & 0.0 & -0.2 & -0.2 & 0.086 \\
\hline & & TO & $-7.4(1.5)$ & $-7.0(1.5)$ & $-6.6(1.8)$ & 0.28 & 0.4 & 0.8 & 0.4 & 0.055 \\
\hline & \multirow{4}{*}{ Transverse } & HS & $-1.2(2.7)$ & $-2.7(4.2)$ & $-2.3(3.4)$ & 0.10 & -1.5 & -1.1 & 0.4 & 0.009 \\
\hline & & HER & $-2.5(2.2)$ & $-3.0(3.4)$ & $-3.8(2.5)$ & 3.20 & -0.5 & $-1.3^{*}$ & -0.8 & 0.232 \\
\hline & & HIR & $2.3(2.0)$ & $3.3(2.8)$ & $3.2(2.6)$ & 0.71 & -1.0 & -0.9 & 0.1 & 0.043 \\
\hline & & TO & $0.2(4.1)$ & $-1.4(5.2)$ & $1.3(4.2)$ & 4.01 & 1.6 & -1.1 & $-2.7^{*}$ & 0.334 \\
\hline \multirow{12}{*}{ Knee } & \multirow{4}{*}{ Sagittal } & HS & $-5.2(1.9)$ & $-5.2(1.5)$ & $-5.0(1.6)$ & 0.27 & 0.0 & 0.2 & 0.2 & 0.025 \\
\hline & & KFX & $6.0(2.3)$ & $8.1(1.7)$ & $9.0(2.6)$ & 3.35 & -2.1 & $-3.0^{*}$ & -0.9 & 0.273 \\
\hline & & KEX & $-6.7(2.2)$ & $-8.3(2.8)$ & $-8.8(3.0)$ & 0.99 & -1.6 & -2.1 & -0.5 & 0.044 \\
\hline & & TO & $17.9(2.3)$ & $16.0(3.0)$ & $14.3(1.5)$ & 2.98 & 1.9 & $3.6^{*}$ & 1.7 & 0.307 \\
\hline & \multirow{4}{*}{ Frontal } & HS & $-2.6(1.4)$ & $-2.2(2.1)$ & $-4.0(2.8)$ & 0.94 & 0.4 & -1.4 & -1.8 & 0.079 \\
\hline & & KAD & $2.1(1.8)$ & $3.9(1.7)$ & $4.9(2.0)$ & 3.78 & $-1.8^{* *}$ & $-2.8^{* *}$ & -1.0 & 0.431 \\
\hline & & $\mathrm{KAB}$ & $-2.2(1.6)$ & $-3.7(2.6)$ & $-3.9(2.8)$ & 0.44 & -1.5 & -1.7 & -0.2 & 0.031 \\
\hline & & TO & $8.9(1.3)$ & $8.2(1.1)$ & 7.7(1.6) & 0.23 & 0.7 & 1.2 & 0.5 & 0.017 \\
\hline & \multirow{4}{*}{ Transverse } & $\mathrm{HS}$ & $-8.7(4.4)$ & $-8.1(6.8)$ & $-10.3(8.5)$ & 0.28 & 0.6 & -1.6 & -2.2 & 0.009 \\
\hline & & KIR & $2.0(3.1)$ & $3.2(2.4)$ & $2.6(3.3)$ & 0.92 & -1.2 & -0.6 & 0.6 & 0.012 \\
\hline & & KER & $-1.2(2.8)$ & $-0.8(2.0)$ & $-1.6(2.0)$ & 0.15 & 0.4 & -0.4 & -0.8 & 0.006 \\
\hline & & TO & $5.0(3.2)$ & $2.1(2.9)$ & $6.3(3.6)$ & 4.03 & $2.9^{* *}$ & -1.3 & $-4.2^{* *}$ & 0.287 \\
\hline \multirow{11}{*}{ Ankle } & \multirow{4}{*}{ Sagittal } & HS & $-1.9(2.7)$ & $-2.3(3.3)$ & $-0.4(4.9)$ & 1.03 & -0.4 & 1.5 & 1.9 & 0.076 \\
\hline & & APF & $-9.1(2.3)$ & $-9.3(2.1)$ & $-6.0(2.6)$ & 2.91 & -0.2 & $3.1^{* *}$ & $3.3^{* *}$ & 0.338 \\
\hline & & $A D F$ & $5.7(2.5)$ & $6.8(2.0)$ & $4.6(1.8)$ & 2.43 & -1.1 & 1.1 & $2.2^{* *}$ & 0.239 \\
\hline & & TO & $-13.8(5.2)$ & $-12.1(4.7)$ & $-17.2(3.6)$ & 2.67 & 1.7 & -3.4 & $-5.1^{*}$ & 0.194 \\
\hline & \multirow{4}{*}{ Frontal } & HS & $0.7(0.6)$ & $0.2(0.9)$ & $0.6(0.6)$ & 1.31 & 0.5 & 0.1 & -0.4 & 0.063 \\
\hline & & AEV & $-2.8(1.6)$ & $-3.1(1.2)$ & $-2.6(1.0)$ & 0.79 & -0.3 & 0.2 & 0.5 & 0.076 \\
\hline & & AIN & $1.2(0.9)$ & $1.9(1.6)$ & $0.5(0.8)$ & 1.03 & -0.7 & 0.7 & 1.4 & 0.071 \\
\hline & & TO & $3.0(3.1)$ & $1.8(2.1)$ & $4.0(3.4)$ & 0.63 & 1.2 & -1.0 & -2.2 & 0.059 \\
\hline & \multirow{3}{*}{ Transverse } & HS & $4.3(1.5)$ & $4.1(2.1)$ & $3.9(2.2)$ & 0.23 & 0.2 & 0.4 & 0.2 & 0.082 \\
\hline & & AER & $-5.1(2.5)$ & $-5.3(2.4)$ & $-7.3(4.2)$ & 0.77 & -0.2 & -2.2 & -2.0 & 0.093 \\
\hline & & TO & $10.5(3.8)$ & $11.2(3.2)$ & $11.7(4.3)$ & 0.60 & -0.7 & -1.2 & -0.5 & 0.057 \\
\hline
\end{tabular}



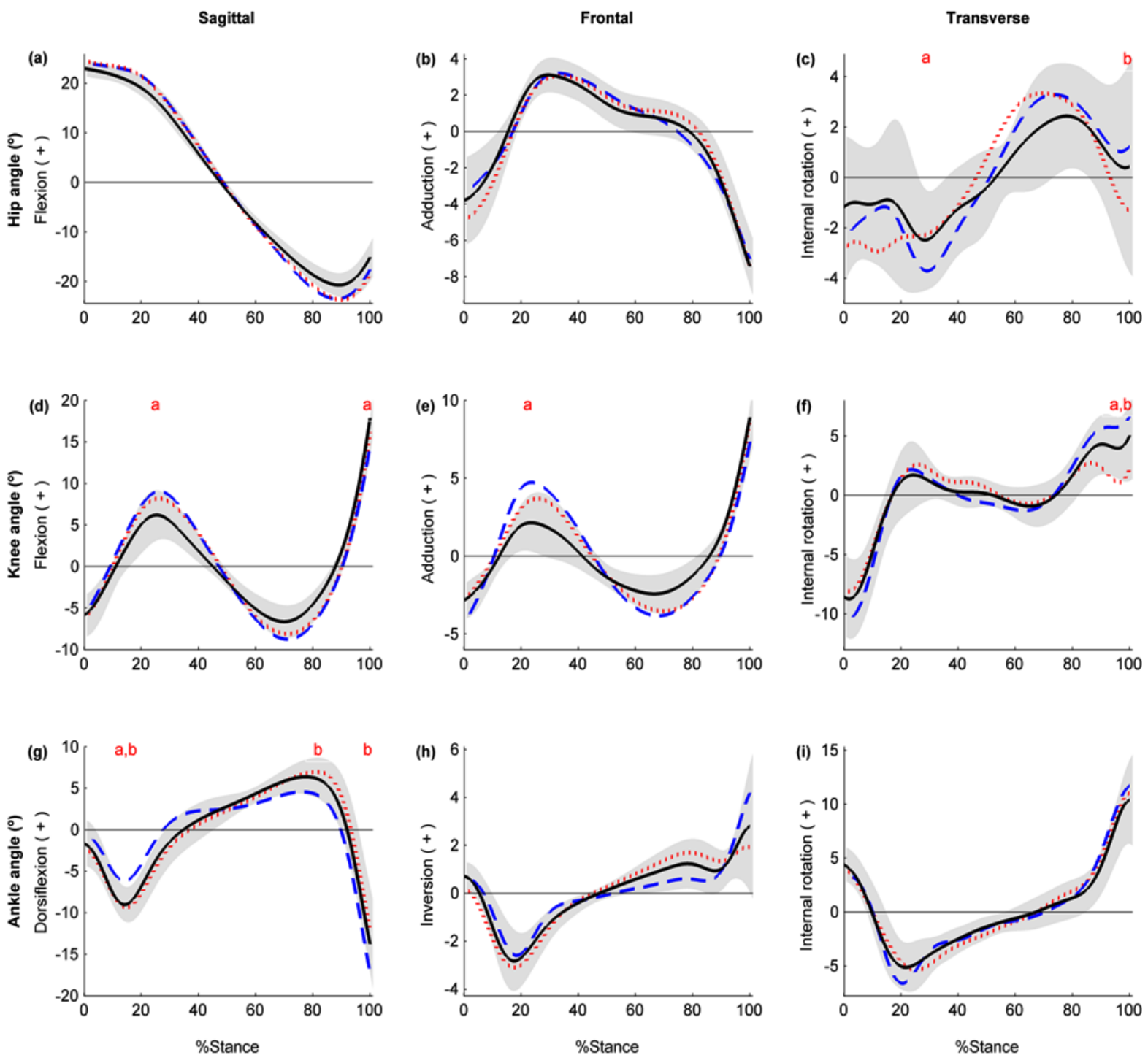

PHYSICAL TREA \MENTS

Figure 1. Three- dimensional angular kinematics for the hip, knee, and angle during stance phase of level walking (LW; mean, solid black line; SD, gray line), inclined walking up-slope (IWU; mean, dotted red line), and down-slope (IWD; mean, dashed blue line). ${ }^{\mathrm{a}}$ and ${ }^{\mathrm{b}}$ represent significant differences between LW vs. other conditions and IWU vs. IWD, respectively.

knee internal rotation decreased significantly during IWU compared with those at LW and IWD conditions (both $\mathrm{P}<0.001$ ). No significant difference was observed in the timing of the selected events for the knee joint $(\mathrm{P}<0.05)$.

Regarding the ankle angles, significant differences during various walking conditions were observed in the sagittal plane (Table 3). More specifically, the APF at IWD was smaller than those of LW and IWU (both $\mathrm{P}<0.001$ ). In addition, the $\mathrm{ADF}$ during IWD was smaller compared to that of IWU $(\mathrm{P}=0.003)$. At TO, a greater plantar flexion was observed during IWD compared to IWU ( $\mathrm{P}=0.023)$. In terms of timing of the events, pairwise comparisons revealed that the ADF during IWD occurred at $75.9 \%$ of stance which was significantly earlier than IWU (84.4\% of stance, $\mathrm{P}=0.014$ ) (Table 4).

\section{Discussion}

The purpose of this study was to determine the effects of cross-slope surfaces on 3D kinematics of the hip, knee, and ankle joints; both the magnitude and timing of the selected events, during stance phase of walking. Overall, the kinematic patterns were similar to the previous studies on level walking [5, 13-15]. However, significant differences were observed in these patterns between the level 
Table 4. Mean (SD) values of timing of the selected events (maximum values) of hip, knee, and ankle angles as a percentage of stance, and associated mean differences, across the intervals of stance phase in level walking (LW), inclined walking up-slope (IWU) and down-slope (IWD).

\begin{tabular}{|c|c|c|c|c|c|c|c|c|c|c|}
\hline \multirow[b]{2}{*}{ Joint } & \multirow[b]{2}{*}{ Plane } & \multirow[b]{2}{*}{ Event } & \multirow[b]{2}{*}{ LW } & \multirow[b]{2}{*}{ IWU } & \multirow[b]{2}{*}{ IWD } & \multirow[b]{2}{*}{$\mathbf{F}$} & \multicolumn{3}{|c|}{ Mean difference (\%) } & \multirow[b]{2}{*}{$\eta^{2}$} \\
\hline & & & & & & & $\begin{array}{l}\text { LW } \\
\text { vs } \\
\text { IWU }\end{array}$ & $\begin{array}{l}\text { LW } \\
\text { vs } \\
\text { IWD }\end{array}$ & $\begin{array}{l}\text { IWU } \\
\text { vS } \\
\text { IWD }\end{array}$ & \\
\hline \multirow{3}{*}{ Hip } & Sagittal & $\mathrm{H}_{\mathrm{EX}}$ & $90.0(1.3)$ & $91.5(1.9)$ & $88.5(2.0)$ & 0.67 & -1.5 & 1.5 & 3.0 & 0.008 \\
\hline & Frontal & $\mathrm{H}_{\mathrm{AD}}$ & $30.3(1.7)$ & $35.2(2.0)$ & $34.5(3.1)$ & 2.34 & $-4.9^{*}$ & -4.2 & 0.7 & 0.271 \\
\hline & Transverse & $\begin{array}{l}\mathrm{H}_{\mathrm{ER}} \\
\mathrm{H}_{\mathrm{IR}}\end{array}$ & $\begin{array}{l}30.0(2.4) \\
78.9(4.0)\end{array}$ & $\begin{array}{l}17.3(2.7) \\
71.5(3.1)\end{array}$ & $\begin{array}{l}32.2(1.8) \\
76.0(3.3)\end{array}$ & $\begin{array}{l}3.18 \\
2.69\end{array}$ & $\begin{array}{c}12.7^{* *} \\
7.4^{*}\end{array}$ & $\begin{array}{c}-2.2 \\
2.9\end{array}$ & $\begin{array}{c}-14.9^{* *} \\
-4.5\end{array}$ & $\begin{array}{l}0.393 \\
0.301\end{array}$ \\
\hline \multirow{3}{*}{ Knee } & Sagittal & $\begin{array}{l}\mathrm{K}_{\mathrm{FX}} \\
\mathrm{K}_{\mathrm{EX}}\end{array}$ & $\begin{array}{l}28.1(4.0) \\
71.8(5.2)\end{array}$ & $\begin{array}{l}28.0(3.7) \\
73.6(4.2)\end{array}$ & $\begin{array}{l}29.3(3.0) \\
73.4(3.8)\end{array}$ & $\begin{array}{l}0.34 \\
0.59\end{array}$ & $\begin{array}{c}0.1 \\
-1.8\end{array}$ & $\begin{array}{l}-1.2 \\
-1.6\end{array}$ & $\begin{array}{c}-1.3 \\
0.2\end{array}$ & $\begin{array}{l}0.011 \\
0.004\end{array}$ \\
\hline & Frontal & $\begin{array}{l}\mathrm{K}_{\mathrm{AD}} \\
\mathrm{K}_{\mathrm{AB}}\end{array}$ & $\begin{array}{l}23.8(2.2) \\
68.7(5.5)\end{array}$ & $\begin{array}{l}27.2(5.7) \\
73.7(7.8)\end{array}$ & $\begin{array}{l}25.9(4.4) \\
72.2(3.4)\end{array}$ & $\begin{array}{l}1.09 \\
0.93\end{array}$ & $\begin{array}{l}-3.4 \\
-5.0\end{array}$ & $\begin{array}{l}-2.1 \\
-3.5\end{array}$ & $\begin{array}{l}1.3 \\
1.5\end{array}$ & $\begin{array}{l}0.103 \\
0.077\end{array}$ \\
\hline & Transverse & $\begin{array}{l}\mathrm{K}_{\mathrm{IR}} \\
\mathrm{K}_{\mathrm{ER}}\end{array}$ & $\begin{array}{l}25.6(7.6) \\
69.6(6.1)\end{array}$ & $\begin{array}{l}29.0(6.3) \\
67.3(7.3)\end{array}$ & $\begin{array}{l}26.2(4.7) \\
62.4(4.1)\end{array}$ & $\begin{array}{l}0.26 \\
0.51\end{array}$ & $\begin{array}{l}-3.4 \\
2.3\end{array}$ & $\begin{array}{c}-0.6 \\
7.2\end{array}$ & $\begin{array}{l}2.8 \\
4.9\end{array}$ & $\begin{array}{l}0.023 \\
0.060\end{array}$ \\
\hline \multirow{3}{*}{ Ankle } & Sagittal & $\begin{array}{l}A_{P F} \\
A_{D F}\end{array}$ & $\begin{array}{l}17.2(3.0) \\
78.8(5.5)\end{array}$ & $\begin{array}{l}17.4(3.4) \\
84.4(7.9)\end{array}$ & $\begin{array}{l}17.4(2.9) \\
75.9(8.3)\end{array}$ & $\begin{array}{l}0.78 \\
0.63\end{array}$ & $\begin{array}{l}-0.2 \\
-5.6\end{array}$ & $\begin{array}{c}-0.2 \\
2.9\end{array}$ & $\begin{array}{l}0.0 \\
8.5^{*}\end{array}$ & $\begin{array}{l}0.009 \\
0.212\end{array}$ \\
\hline & Frontal & $\begin{array}{l}A_{E V} \\
A_{I N}\end{array}$ & $\begin{array}{l}18.0(2.7) \\
78.8(3.5)\end{array}$ & $\begin{array}{l}18.4(3.0) \\
79.3(2.1)\end{array}$ & $\begin{array}{l}18.2(2.9) \\
77.1(4.0)\end{array}$ & $\begin{array}{l}0.13 \\
0.27\end{array}$ & $\begin{array}{l}-0.4 \\
-0.5\end{array}$ & $\begin{array}{c}-0.2 \\
1.7\end{array}$ & $\begin{array}{l}0.2 \\
2.2\end{array}$ & $\begin{array}{l}0.033 \\
0.002\end{array}$ \\
\hline & Transverse & $A_{E R}$ & $22.2(5.1)$ & $27.8(3.6)$ & $20.8(6.6)$ & 0.80 & -5.6 & 1.4 & 7.0 & 0.006 \\
\hline
\end{tabular}

$* * \mathrm{P}<0.01$

and cross-slope conditions, as well as asymmetrical differences between the up-slope and down-slope leg. Presumably without such compensations on the cross-slope surfaces, the up-slope and down-slope limbs may not be able to both avoid lateral falling and maintain a steady forward locomotion.

Walking in different surface conditions caused kinematic adaptations in the sagittal plane for the knee and ankle joints. A greater maximum knee flexion was accompanied by a smaller ankle plantar flexion at IWD in the first $30 \%$ of stance. Owing to the fast falling of body center of mass (COM) during stepping at down-slope, as indicated by greater vertical ground reaction force [16], higher knee flexion might partially compensated the greater loading response posed during IWD leading to a softer landing from HS to the first $30 \%$ of stance.

In the meantime, decreased plantar flexion was ensured lengthening of down-slope limb. In agreement with the findings of Dixon and Pearsall [5] and Walsh et al. [17], on the down-slope side, subjects attempted to increase their functional leg-length by decreasing dorsiflexion during mid-stance and increasing plantar flexion at TO (Table 3, Figure $1 \mathrm{~g})$. In addition, decreased knee flexion at TO during IWD was a compensatory mechanism to lengthen the down-slope limb. Without compensation of the lower limbs on the cross-slope surface, the up-slop and down-slop limb would be either too long or too short, respectively, to permit comfortable locomotion and vertical balance [18].

Knee abduction/adduction harmony with knee flexion/ extension (Figure 1d and 1e) played an important role in adjusting the functional leg-length during different phases to maintain subtle gait pattern and medio-lateral balance. In the frontal plane, greater knee adduction from HS to the first $30 \%$ of stance during IWU and IWD indicated the greater effort required to transfer the body COM to up the slope, and shifting of body COM towards down-slope, respectively. This assumption is supported by the ground reaction force adaptations observed during cross-slope walking [16].

In the transverse plane, the hip kinematic alterations during various walking conditions showed 2 distinct patterns: 1) an external rotation in the first half of stance, and 2) an internal rotation from mid-stance through the second half of stance. Our results revealed significant differences in these patterns between the level and cross-slope conditions, with down-slope hip being more externally rotated by $1.3^{\circ}$, as well as asymmetrical differences between the up-slope (externally rotated) and down-slope (internally rotated) hips (Figure 1c).

These compensatory mechanisms may work in order to minimize both the medio-lateral displacement of body COM during walking on cross-slope surfaces and movement perturbations in the other joints, thereby reducing en- 
ergy expenditure. Furthermore, significantly smaller KIR at TO during IWU compared to the other surface conditions facilitated the up-slope hip external rotation, thereby shifting body COM to the up-slope edge of the walkway to attain stability (Table 3, Figure 1c and 1f).

In general, while during walking on different cross-slope conditions, knee and ankle joints had the most kinematic adaptations in the sagittal plane. These alterations in the transverse plane were mainly observed in hip and knee joints. Our findings showed that knee, as the only lower extremity joint with 3D kinematic alterations, played an essential role to maintain balance and forward locomotion during level and cross-slope walking.

Variations in timing of the selected kinematic events for the level and cross-slope walking showed that hip and ankle joints are mainly affected by the surface conditions. However, the temporal aspects of the kinematic adaptations were more consistent than their magnitude (Tables 4). Begg et al. [19] and Shapiro et al. [20] reported timing consistency in human gait and proposed that such consistencies reflect motor programs for movement control in which a stored sequence of motor commands can be individualized to meet specific tasks demands. Thus, in cross-slope gait the relative timing of the joints kinematic events is specified by a motor program with the 3D joint angles scaled up or down depending on transverse inclination angle.

Although this study provides insight into the 3D kinematics of the hip, knee, and ankle joints during cross-slope walking, it has a few limitations. To fully evaluate the cross-slope walking, the kinematic alterations of hip, knee, and ankle during the swing phase should be studied, as well. In addition, how other populations (e.g. females, children, elderly, and individuals with lower extremity injuries) would modify the kinematics of their lower extremity joints during cross-slope walking is unknown. Therefore, the findings of this study may not completely represent the cross-sloped walking kinematics in those populations. Further research is required to address these concerns.

This study showed that walking on cross-slope surfaces require substantial and asymmetrical 3D kinematic adaptations of hip, knee, and ankle. The highest variability were observed in the sagittal plane kinematics of knee and ankle, (to ensure shortening/lengthening of up-slop and down-slope limbs, respectively) and the transverse plane of hip and knee (to minimize medio-lateral displacement of body COM during cross-slope walking). These kinematic adaptations are necessary to have a subtle walking while maintaining dynamic medio-lateral balance. Similar to previous findings, the temporal aspects of the kinematic adaptations were more consistent than their magnitude. This information enriches our understanding about kinematic adaptations of the lower extremity joints in stance phase during level and cross-slope walking.

\section{Acknowledgements}

The current research hasn't received any financial support.

\section{Conflict of Interests}

The authors declared no conflict of interests.

\section{References}

[1] Allard P, Lachance R, Aissaoui R, Duhaime M. Simultaneous bilateral 3-D able-bodied gait. Human Movement Science. 1996; 15(2):327-46.

[2] Rose J, Gamble JG. Human Walking. $3^{\text {rd }}$ ed. Philadelphia: Lippincott Williams and Wilkins; 2006.

[3] Winter DA. Kinematic and kinetic patterns in human gait: variability and compensating effects. Human Movement Science. 1984; 3:51-76.

[4] Nicolaou M, Pearsall DJ, Loh J. Gait adaptation to transverse slopes. Paper presented at: The $4^{\text {th }}$ World Congress for Biomechanics; 2002 Aug 4-9; Calgary, Canada.

[5] Dixon CP, Pearsall DJ. Gait dynamics on a cross-slope walking surface. Journal of Applied Biomechanics. 2010 26(1):17-25.

[6] Damavandi M, Dixon CP, Pearsall DJ. Kinematic adaptations of the hindfoot, forefoot, and hallux during cross-slope walking. Gait and Posture. 2010; 32(3):411-15.

[7] Sussman DH, Walker M, Tamburello M, VanLunen B, Dowling E, Atkinson R, et al. The effect of road camber on running kinematics. Paper presented at: The $14^{\text {th }}$ International symposium on biomechanics in sports; 2001 Jun 23-26; San Francisco, USA

[8] Pollard H, Sim P, McHardy A. Lateral ankle injury: Literature review and report of two cases. Journal of the Chiropractic and Osteopathic College of Australasia. 2002; 10(1):21-30.

[9] Lockhart TE, Spaulding JM, Park SH. Age-related slip avoidance strategy while walking over known slippery floor surface. Gait and Posture. 2007; 26(1):142-49.

[10] Grood E, Suntay W. A joint coordinate system for the clinical description of three-dimensional motion: applications to the knee. Journal of Biomechanical Engineering. 1983; 105:136-43.

[11] Nester CJ, Van der Linden ML, Bowker P. Effect of foot orthoses on the kinematics and kinetics of normal walking gait. Gait and Posture. 2003; 17(2):180-87.

[12] Dicharry J. Kinematics and kinetics of gait: from lab to clinic. Clinical Sports Medicine. 2010; 29(3):347-64 
[13] McMillan AG, Pulver AME, Collier DN, Williams DSB. Sagittal and frontal plane joint mechanics throughout the stance phase of walking in adolescents who are obese. Gait and Posture. 2010; 32(2):263-68.

[14] Russell EM, Hamill J. Lateral wedges decrease biomechanical risk factors for knee osteoarthritis in obese women. Journal of Biomechanics. 2011; 44(12):2286-291.

[15] Cappozzo A. Three-dimensional analysis of human walking: experimental methods and associated artifacts. Human Movement Science. 1991; 10(5):589-602.

[16] Damavandi M, Dixon CP, Pearsall DJ. Ground reaction force adaptations during cross-slope walking and running. Human Movement Science. 2012; 31(1):182-89.

[17] Walsh M, Connolly P, Jenkinson A, O'Brien T. Leg length discrepancy-an experimental study of compensatory changes in three dimensions using gait analysis. Gait and Posture. 2000; 12(2):156-61.

[18] Kaufman KR, Miller LS, Sutherland DH. Gait asymmetry in patients with limb-length inequality. Journal of Pediatric Orthopaedics. 1996; 16(2):144-50.

[19] Begg RK, Sparrow WA, Lythgo ND. Time-domain analysis of foot-ground reaction forces in negotiating obstacles. Gait and Posture. 1998; 7(2):99-109.

[20] Shapiro DC, Zernicke RF, Gregor RJ, Diestel JD. Evidence for generalized motor programs using gait pattern analysis. Journal of motor behavior. 1981; 13(1):33-47. 